\title{
Repositorios para la transferencia del conocimiento abierto en las instituciones culturales privadas
}

\author{
Maximiliano Barrios Felipe | Fundación Santa María la Real \\ URL de la contribución <www.iaph.es/revistaph/index.php/revistaph/article/view/4674>
}

La producción científica de las instituciones culturales es, como se afirma en la presentación de este debate, una de las principales señales para evaluar la calidad de las organizaciones. Si a esto unimos que estos contenidos sean visibles y fácilmente accesibles, en consonancia con la idea de ciencia abierta, les estaremos procurando un mayor valor si cabe, ya que esos recursos y la propia institución podrán ser citados en distintos foros y el impacto será extensible a un público exponencialmente mayor.

Las consecuencias no son nada desdeñables pues permiten darse a conocer entre la comunidad científica y los gestores públicos o privados responsables de cómo administrar los recursos y con quién aventurarse en ciertos proyectos. En cierto modo, y si se cuidan los contenidos, es lógico conseguir crearse un cierto prestigio que incrementará las posibilidades de acceder a distintos recursos o colaboraciones sin aumentar considerablemente la inversión. En este debate abierto muchos de los planteamientos expresados son totalmente válidos para las instituciones públicas cuya misión es procurar ofrecer a sus ciudadanos servicios culturales y científicos, fomentar y difundir la investigación y finalmente ser garantes de la salvaguarda del conocimiento.

Sin embargo, en el caso que atañe a las organizaciones privadas, esta filosofía de ciencia abierta necesita de un retorno lo suficientemente importante para lograr mantener sus objetivos comerciales porque en ello va su propia supervivencia como institución. Por experiencia, creo que es interesante confluir hacia un modelo mixto en el cual cohabiten las necesidades de la organización con las de los ciudadanos de tal forma que permitan proteger parte de la producción creada por la institución durante los años necesarios para que se

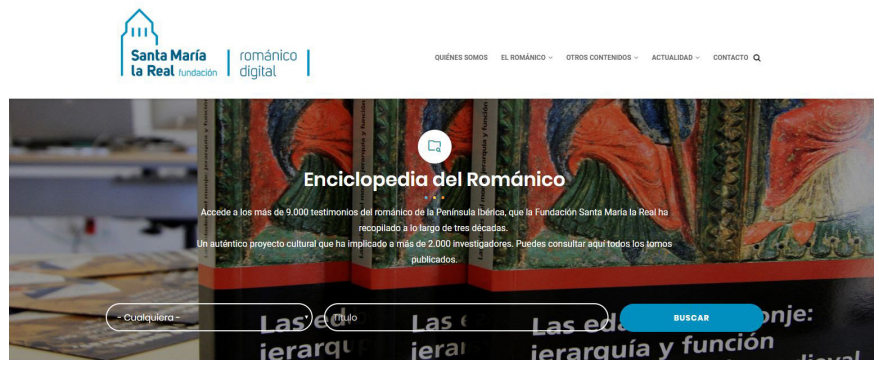

Captura de la web Románico Digital

cumpla su recorrido venal. A partir de ese momento es cuando llega la oportunidad de devolver a la sociedad los réditos logrados. Esto no es óbice para que junto a este modelo convivan también otros casos en los que desde su nacimiento los recursos culturales y científicos sean liberados, ya que permitirán también servir de plataforma para la visibilidad de la propia institución, para algún objetivo estratégico en un momento dado y, como decíamos anteriormente, aumentar el prestigio de la institución que sirva para posicionarse como referente de calidad.

La Fundación Santa María la Real cumple con algunos de los enunciados citados anteriormente. No se trata de una institución pública en cuanto que sus recursos no emanan de los presupuestos del aparato del Estado; sin embargo, su vocación sí es pública en tanto en cuanto sus objetivos van encaminados a un interés general: promover la conservación, restauración y puesta en valor de los bienes integrantes de nuestro patrimonio cultural, natural y social, así como facilitar su conocimiento y difusión.

Desde hace más de 30 años, en cumplimiento de esas premisas, tiene a sus espaldas una ingente producción científica producto de sus cursos sobre arte e historia 
a debate Repositorios y redes sociales académicas para la transferencia del conocimiento abierto

| coordina Remedios Melero Melero

medievales y un catálogo de publicaciones con más de 200 títulos.

Mucha de esta producción es compartida de forma abierta desde hace una década, con especial atención a su revista científica Codex Aquilarensis, y en breve lo será con su publicación más emblemática, La Enciclopedia del Románico en la Península Ibérica, la magna obra que se cierra este año con 60 volúmenes tras la incorporación de Lleida y Girona, que nutrirá la nueva y remozada www.romanicodigital.com que será lanzada en este año.

Uno de los aspectos primordiales que los contenidos en abierto deben cuidar para evitar reticencias por parte de los productores es la necesidad de garantizar que la titularidad de los derechos de los autores y de la propia organización queden salvaguardados, pero asistimos a que todavía no hay un marco legal diáfano.

Por otra parte, se apuntaba en este debate la posibilidad de que estos contenidos se compartieran y ofrecieran en multiplicidad de plataformas lo que a mi juicio pervierte y enmascara la fuente original, que a pesar de que pudiera ser citada como es obligado, puede perderse en una enmarañada y tupida red de portales de dudoso contenido y finalmente disolver su trazabilidad en el océano de la información. Es cierto que los recolectores como Europeana son una poderosa herramienta y solventan por sí solos esta problemática, pero no es menos cierto que cuando hablamos de información digital lo hacemos de un material excesivamente sensible al cambio y a su pérdida definitiva por diversos factores, desde la obsolescencia tecnológica a la desaparición del portal que la generó. No estamos vacunados contra las vicisitudes del futuro y aunque los repositorios públicos pueden presumir de un periodo de vida sine díe, las organizaciones privadas no tienen asegurada su supervivencia y con su desmantelamiento se pueden perder para siempre contenidos de gran valor.

Más útil para garantizar la perdurabilidad y el acceso libre al contenido es el modelo DOI, pero dada la enormidad

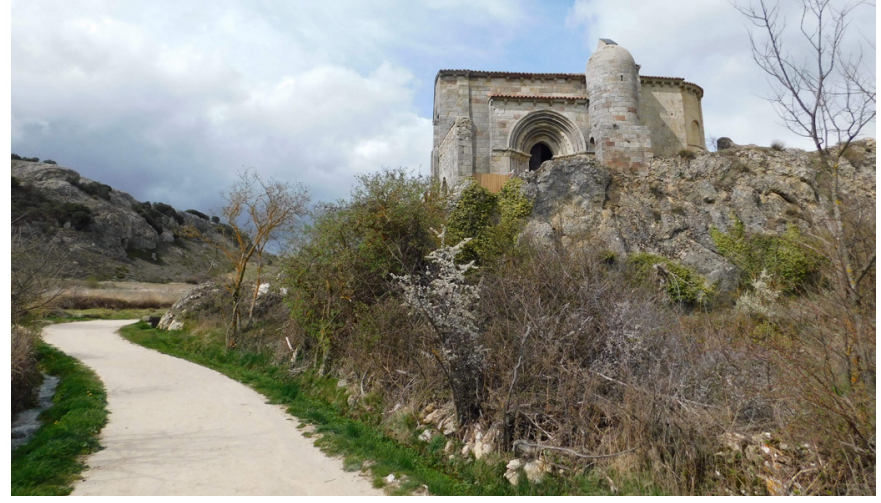

Ermita de Santa Cecilia en Vallespinoso de Aguilar. Una de las joyas románicas del entorno de Aguilar de Campoo | foto Fundación Santa María la Real (Fernando Castillo Usero)

de la información a registrar, en algunos casos lo hace inviable para según qué cosas, por ejemplo, si estamos hablando de más de 15.000 urls, con un coste inasumible para ciertas organizaciones. Es aquí cuando precisamente las autoridades públicas deberían garantizar la preservación electrónica de los resultados de investigación a largo plazo, comprometiendo para ello parte de los recursos destinados a la promoción de la cultura e investigación científica. Facilitar, promover y cofinanciar estas políticas servirá para que el modelo de ciencia abierta tenga un recorrido largo y provechoso para todos.

La proliferación de plataformas comerciales puede deberse precisamente a esto: las obligaciones inherentes del sector público respecto a la universalidad y gratuidad de sus contenidos puede retraer a ciertos autores o instituciones que ven comprometida parte de su producción sin obtener a cambio un beneficio que enjuague al menos en parte los esfuerzos realizados. Junto a ello, no hay un decidido impulso por apuntalar la colaboración con el partenariado privado sin comprometer un cierto beneficio económico. Tampoco se apuesta por convertirse en solitario o mejor aún en alianza con entidades supranacionales de carácter europeo en Agencia de Registro Pública para otorgar el Digital Object Identifier (DOI) correspondiente y mitigar las necesidades de instituciones culturales no públicas que garanticen que sus contenidos estén siempre disponibles. 